13

\title{
Интеркалирование платиной графеновой пленки, образованной на карбиде молибдена $\mathrm{Mo}_{2} \mathrm{C}$
}

\author{
() Е.В. Рутьков, Е.Ю. Афранасьева, Н.Р. Галль \\ Физико-технический институт им. А.Ф. Иофффе РАН, \\ 194021 Санкт-Петербург, Россия \\ e-mail: rutkov@ms.ioffe.ru
}

(Поступило в Редакцию 20 февраля 2018 г.)

Показано, что напыление атомов платины на графен на карбиде молибдена $\mathrm{Mo}_{2} \mathrm{C}$ при $T=1000 \mathrm{~K}$ приводит к интеркалированию графена платиной. При этом под графеном растет многослойная сплошная пленка платины, что позволяет в сложном оже-спектре углерода выделить составляющие, отвечающие только графену.

DOI: $10.21883 / J T F .2018 .12 .46799 .81-18$

В наших работах [1,2] обнаружен и исследован эффект интеркалирования графеновых пленок чужеродными атомами $\mathrm{Na}, \mathrm{K}, \mathrm{Cs}, \mathrm{Si}, \mathrm{C}, \mathrm{Mo}, \mathrm{Al}, \mathrm{Ag}, \mathrm{Ba}, \mathrm{Ir}, \mathrm{Cu}, \mathrm{Pt}$ на разных металлических подложках $\operatorname{Re}(\mathrm{I} 0 \overline{1} 0), \operatorname{Rh}(\mathrm{III})$, $\mathrm{Ni}(\mathrm{III}), \operatorname{Ir}(\mathrm{III})$ [2,3]. Предложен механизм интеркалирования через дефекты графенового слоя [2].

Графеновую пленку на металлах интеркалируют и молекулы фуллеренов $\mathrm{C}_{60}[4,5]$, что представляет большой практический интерес, так как позволяет изолировать графен от металлической подложки. В частности, попытка изолировать графен от металла предпринималась во многих работах с помощью интеркалирования кислорода под графен с целью создания диэлектрического окисного слоя [6-8].

Кроме металлической подложки процесс интеркаляции изучается на графене, образованном на карбиде кремния [9-11]. В связи с этим важным представляется вопрос о влиянии подложки на процесс интеркалирования, в частности вопрос о том, в какой мере обнаруженные ранее закономерности справедливы при использовании карбида металла вместо самого металла.

В настоящей работе изучается интеркалирование платиной графена на карбиде молибдена $\mathrm{Mo}_{2} \mathrm{C}$.

Опыты проводили в сверхвысоковакуумном ( $P \sim 10^{-10}$ Torr $) \quad$ оже-спектрометре высокого разрешения $(\Delta E / E \sim 0.1 \%)$ [2]. В установке имелся модуль, позволяющий реализовать комбинированный метод термоэлектронной эмиссии и поверхностной ионизации [3]. В частности, был использован метод зондирования поверхности потоком молекул $\mathrm{CsCl}$, который крайне чувствителен к качеству (дефектности) графенового слоя [2,3].

В качестве образцов использовались прямонакальные молибденовые ленты размерами $0.02 \times 1 \times 40 \mathrm{~mm}^{3}$. Работа выхода поверхности составляла $е \varphi=4.4 \mathrm{eV}$, что соответствовало грани (100).

Атомы Pt напылялись путем сублимации с платиновых лент, нагретых до $T \approx 1900 \mathrm{~K}$.
Графен образовывали традиционным для нас способом - крекингом на нагретом до $T_{\mathrm{H}}=1700 \mathrm{~K}$ образце напускаемых в прибор молекул $\mathrm{C}_{6} \mathrm{H}_{6}$. В работах $[2,3,12,13]$ подробно описана методика образования слоя графена, его свойства и характеризация, в том числе приводятся доказательства, что образуется только один сплошной слой графена. Процесс науглероживания проходит следующие фазы: формирование на поверхности карбида $\mathrm{MoC}$, формирование в приповерхностной области объемного карбида $\mathrm{Mo}_{2} \mathrm{C}$ и его прорастание по всей толщине ленты и завершающая стадия - образование на поверхности сплошной пленки графена. На пассивной поверхности графена диссоциация молекул бензола прекращается, и толщина пленки в один слой сохраняется.

Изменения температуры науглероженного при $T_{\mathrm{H}} \mathrm{H}$ молибдена приводят к следующему. При $T>T_{\mathrm{H}}+70^{\circ}$ графен разрушается, атомы углерода растворяются в объеме $\mathrm{Mo}_{2} \mathrm{C}$. При понижении температуры до $T=T_{\mathrm{H}}$ на поверхности быстро восстанавливался слой графена путем выделения углерода из пересыщенного твердого раствора. При $T<T_{\mathrm{H}}-100^{\circ}$ на поверхности формируется толстая графитовая пленка. При $T \leq 1000 \mathrm{~K}$ выделение углерода прекращается, так как „замораживается“ диффузия атомов углерода в объеме образца. Резкое уменьшение температуры (выключение тока накала ленты) от $T_{\mathrm{H}}$ до комнатной сохраняет слой графена в диапазоне $300-1000 \mathrm{~K}$.

На рис. 1 показано изменение оже-сигнала углерода 1 , платины 2 и молибдена 3 при напылении атомов платины при $T=1000 \mathrm{~K}$ на графен, образованный на карбиде молибдена. Видно, что с течением времени оже-сигнал молибдена уменьшается до уровня шумов прибора, а оже-сигнал платины растет и достигает максимального значения при $t \geq 300 \mathrm{~s}$.

Как показано в работе [14], атомы Pt охотно интеркалируют графен на $\operatorname{Ir}(111)$, накапливаясь под слоем в неограниченном количестве. Разумно ожидать, что и в данном опыте атомы Pt диффундируют под графеновый 


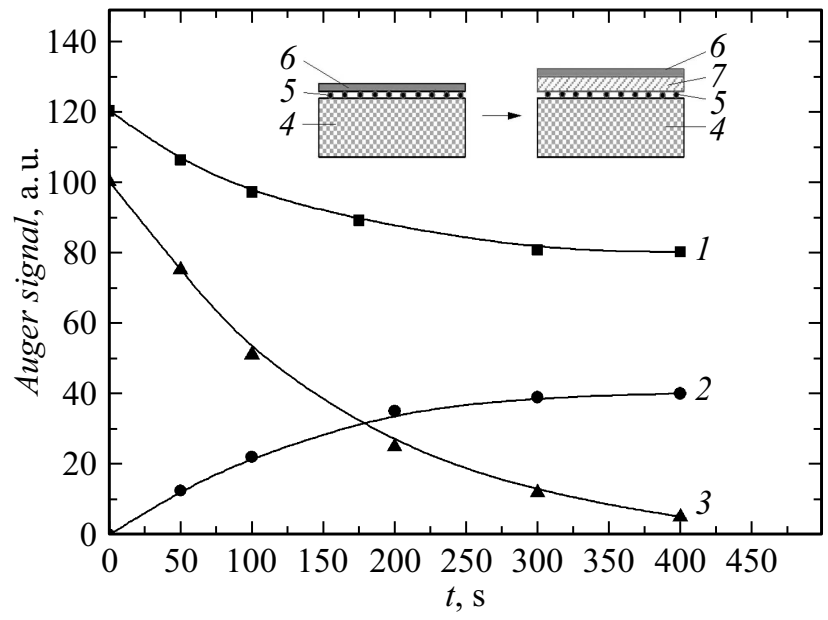

Рис. 1. Изменение интенсивности оже-сигналов углерода 1 , платины 2 и молибдена 3 от времени напыления атомов платины при $T=1000 \mathrm{~K}$ на пленку графена, образованную на карбиде молибдена $\mathrm{Mo}_{2} \mathrm{C}$. На врезке - модельная иллюстрация: 4 - подложка (объемный карбид молибдена $\left.\mathrm{Mo}_{2} \mathrm{C}\right), 5-$ поверхностный углерод в фазе поверхностного химического соединения МоC, 6 - слой графена, 7 - слой платины.

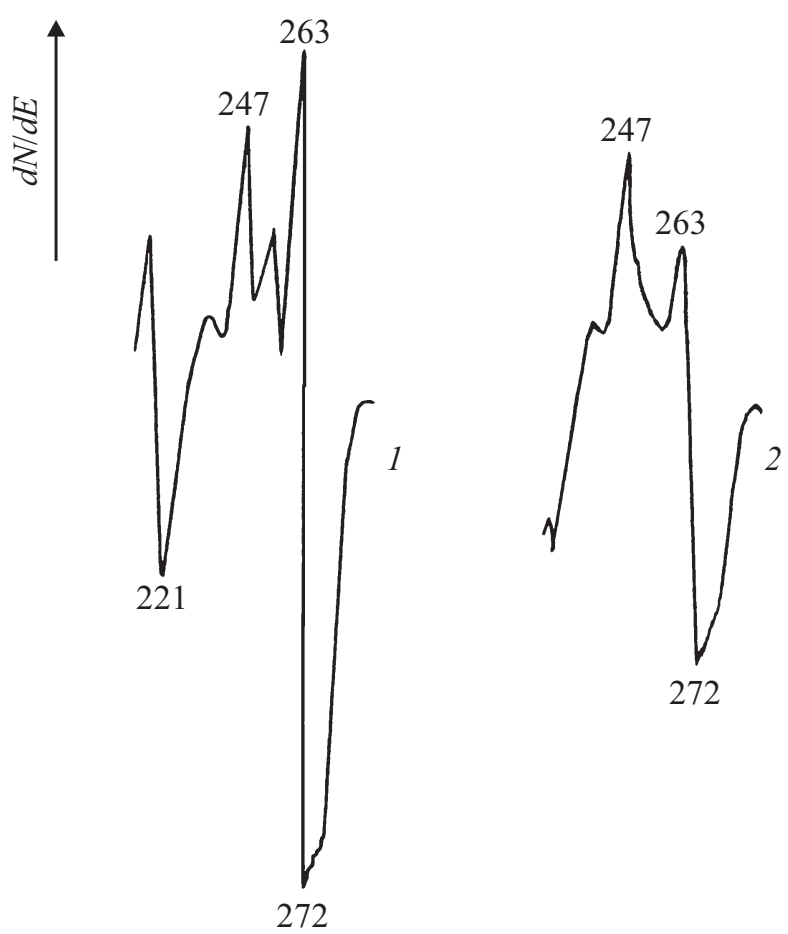

Рис. 2. Оже-спектры углерода: 1 - графен, образованный на объемном карбиде $\mathrm{Mo}_{2} \mathrm{C}$, на поверхности которого под графеном находится поверхностный карбид $\mathrm{MoC} ; 2-$ после образования под графеном толстой пленки платины.

„ковер“. При этом уменьшение интенсивности ожесигнала молибдена до уровня шумов говорит о том, что толщина пленки платины стала больше 6-7 слоев предельная чувствительность для метода ЭОС [2,3], а также о том, что растущая пленка платины сплошная, а не островковая.

В отличие от работы [14], в которой оже-сигнал углерода остается неизменным, в настоящей работе он существенно уменьшается. Это связано с тем, что оже-спектр углерода здесь является суперпозицией трех спектров - графена, поверхностного карбида МоС и объемного карбида $\mathrm{Mo}_{2} \mathrm{C}$ (рис. 1, врезка). Поэтому форма оже-спектра необычная (рис. 2, спектр 1), не похожая на спектры графена на других подложках. Пленка платины экранирует поверхностный и объемный карбиды и оже-спектр углерода становится типичным для графена $[2,3]$ (рис. 2, спектр 2 и рис. 1, врезка).

Таким образом, показано, что явление интеркалирования графена чужеродными атомами носит универсальный характер и не зависит от природы подложки, реализуясь и на чистых металлах (Ir, Rh, Ni, Re) или их карбидах $\left(\mathrm{Mo}_{2} \mathrm{C}\right)$. Это еще раз подчеркивает, что графен представляет собой самостоятельную структурную единицу - двумерный кристалл. Образование многослойной пленки $\mathrm{Pt}$ под графеном в настоящей работе оказалось оригинальным способом выделить в оже-спектроскопии составляющую, связанную только с пленкой графена.

Факт образования многослойной пленки интеркалята $(\mathrm{Pt})$ под графеном вселяет надежду, что правильный подбор температуры подложки и плотности потока адсорбата позволит использовать „неметаллические“ атомы, например кремний, для создания диэлектрической прослойки между графеном и металлом, где последний может выступать в качестве готового электрического контакта.

\section{Список литературы}

[1] Рутьков Е.В., Тонтегоде А.Я. // УФН. 1993. Т. 163. Вып. 11. C. 57-74. [Tontegode A.Ya., Rut'kov E.V. // Physics Uspekhi. 1993. Vol. 36. N 11. P. 1053-1067.]

[2] Gall N.R., Rut'kov E.V. Physics and Applications of Graphene - Experiments / Ed. by S. Mikhailov. Rijeca-L.: Intech Open Access Publisher, 2011. P. 293-326.

[3] Gall N.R., Rut'kov E.V., Tontegode A.Ya. // Int. J. Modern Phys. B. 2997. Vol. 11. N 16. P. 1865-1911.

[4] Rut'kov E.V., Tontegode A.Ya., Usufov M.M. // Phys. Rev. Lett. 1995. Vol. 74. N 5. P. 758-760.

[5] Gall N.R., Rut'kov E.V., Tontegode A.Ya., Usufov M.M. // Mol. Mat. 1996. Vol. 7. P. 187-190.

[6] Hui Zhang, Qiang Fu, Yi Cui, Dali Tan, Xinhe Bao. // J. Phys. Chem. C. 2009. Vol. 113. N 19. P. 8296-8301.

[7] Granås E., Knudsen J., Schröder U.A., Gerber T., Busse C., Arman M.A., Schulte K., Andersen J.N., Michely T. // ASC Nano. 2012. Vol. 6. N 11. P. 9951-9963.

[8] Larciprete R., Ulstrup S., Lacovig P., Dalmiglio M., Bianchi M., Mazzola F., Hornekar L., Orlando F., Baraldi A., Hofmann P., Lizzit S. // ASC Nano. 2012. Vol. 6. N 11. P. 9551-9558.

[9] Sugavara K., Kanetani K., Sato T., Takahushi T. // Aip Advan. 2011. Vol. 1. P. 022103 (1-5). 
[10] Sicot M., Fugot-Revurat Y., Kierren B., Vasseur G., Malterre D. // Appl. Phys. Lett. 2014. Vol. 105. P. 191603 $(1-5)$

[11] Meng L., Wu R., Zhou H., Zhang Y., Li L., Wang Y. // Appl. Phys. Lett. 2012. Vol. 100. P. 083101 (1-4).

[12] Waqar Z., Makarenko I.V., Titkov A.N., Gall N.R., Rut'kov E.V., Tontegode A.Ya. // J. Mater. Res. (JMR). 2004. Vol. 19. N 4. P. $1058-1061$.

[13] Kluzek Z., Kozlowski W., Waqar Z., Patta S., BuenellGray J.S., Makarenko I.V., Gall N.R., Rut'kov E.V., Tontegode A.Ya., Titkov A.N. // Appl. Surf. Sci. 2005. Vol. 252. N 5. P. $1221-1227$.

[14] Галль Н.Р., Рутьков Е.В., Тонтегоде А.Я. // Письма в ЖТФ. 1988. Т. 14. Вып. 6. С. 527-532. 